\title{
Unconjugated Neonatal Hyperbilirubinemia: Evaluation and \\ Treatment
}

\author{
Zaid T Yaseen $(\mathrm{PhD})^{1}$, Jalil I Alezzi $(\mathrm{PhD})^{2}$ and Suad M Khaleel $(\mathrm{DCH})^{3}$ \\ Abstract
}

Background: Neonatal jaundice is a common problem with a lot of faults that may happen during its management.

Objective:To study the epidemiological features of the unconjugated hyperbilirubinemia(UHB)in Diyala Governorate and discuss the proper lines of therapy, as well as to discuss the daily practice adopted in our hospital, and its complications.

Patients and Methods: A cross-sectional study included 100 neonates (term and preterm babies) with unconjugated hyperbilirubinemia aged 0-7 days who were admitted to the AlBatool Teaching Hospital in Baqubah, Iraq, from $1^{\text {st }}$ February 2018 to the $1^{\text {st }}$ November 2018. Term infants with total serum bilirubin (TSB) $\geq 22 \mathrm{mg} / \mathrm{dL}$ were treated with exchange transfusion and phototherapy (Group A, 44 neonates). Those with total serum bilirubin levels from $13-<22 \mathrm{mg} / \mathrm{dL}$ were treated with phototherapy only (Group B, 56 neonates). These decisions were made according to the TSB level and risk factors.

Results: Forty-eight percent of neonates had hemolytic causes (Rh-isoimmunization 13\%; ABO-incompatibility 10\%; G6PD-deficiency 25\%). Other include: sepsis 8\%; prematurity 33\%; congenital CMV infection 1\%; and there were 10\% had no evidence of hemolysis or other serious problems. The mortality rate was $3.8 \%$ of those who had an exchange transfusion.

Conclusion: The decision of kind of treatment is dependent on the underlying etiology of unconjugated hyperbilirubinemia.

Keywords: Unconjugated hyperbilirubinemia, Neonates, complications

Corresponding Author: jalilkadim@gmail.com

Received: $26^{\text {th }}$ April 2020

Accepted: $12^{\text {th }}$ August 2020

DOI:https://doi.org/10.26505/DJM.19025330426

\footnotetext{
${ }^{1}$ Albatool Teaching Hospital - Diyala- Iraq

${ }^{2}$ College of Medicine-University of Diyala- Diyala- Iraq

${ }^{3}$ AlRamadi Teaching Hospital for Obstetrics and Pediatrics -Ramadi- Iraq
}

\section{Introduction}

Hyperbilirubinemia (defined as a TB $>95$ th percentile on the hour-specific Bhutani nomogram [1,2]. Hyperbilirubinemia with a $\mathrm{TB}>25$ to $30 \mathrm{mg} / \mathrm{dL}$ is associated with an augmented risk for bilirubin-induced

neurologic dysfunction (BIND) [3,4]. In developed countries, the incidence of "extreme" hyperbilirubinemia was 0.03 percent of live births [5]. Initial tests that should be obtained are Blood group and $\mathrm{Rh}$ 
and direct Coombs test $\mathrm{CBC}$ and smear. Reticulocyte countGlucose-6-phosphate dehydrogenase (G6PD) measurement, if clinically appropriate[6,7].No data showing that phototherapy improves neurodevelopmental outcomes, but it reduces the likelihood that hyperbilirubinemia reaches a level associated with the risk of kernicterus [[8,9]. Exchange transfusion usually reduces total serum bilirubin (TSB) by about $50 \%[10,11]$. Studies reported mortality rates around $0.3 \%$ associated with the procedure [12,13] and a significant complication rate of $1 \%$ [14]. When infants managed suitably, the outcome is excellent with minimal or no additional risk for adverse neurodevelopmental sequelae $[15,16]$. There were no reported cases of kernicterus after the implementation of treatment guidelines for hyperbilirubinemia [17].In developed countries, the results revealed no difference in development at 1-5 years of age from controls matched by gender, age, gestational age, and the municipality of residency[16,18]. The prevalence of kernicterus in premature infants is uncertain. There were reports of around a $4 \%$ rate of kernicterus based upon characteristic postmortem neuropathological findings preterm infants who died after 48 hours of life $[8,18]$. The aim of this study is to evaluate the epidemiological features of the UHB in Albatool Teaching Hospital and discuss the proper lines of therapy, and its complications.

\section{Patients and Methods}

A cross-sectional study involved 100 neonates with unconjugated hyperbilirubinemia, whose ages ranged from
0-7 days admitted to AlBatool teaching hospital for Gynecology and Obstetrics. and Pediatrics, Baqubah city, Diyala Province, Iraq, from $1^{\text {st }}$ of February 2018 to $1^{\text {st }}$ of November 2018. These infants were seen initially in the emergency department of the hospital, either due to referral from a physician for neonatal jaundice or jaundice noticed by the family. After proper clinical assessment, the gestational ages were estimated according to maternal history of last menstrual period, U/S reports, and clinical assessment of the infants by using "Pellard scoring system" for assessment of gestational ages in the $1 \mathrm{st} 48 \mathrm{hr}$. of life [12].

A heel- prick was done and a sample of capillary blood was taken by a capillary tube. Hematocrit was measured by a special ruler and TSB was measured by a bilirubin analyzer (Bilirubinmeter, Bil Read, Optima; serial no. 9423; prod. June 1995). As well as blood group and $\mathrm{Rh}$. were done Then according to the TSB level of the infant, the line of treatment was decided either phototherapy or exchange transfusion. Term infants with $\mathrm{TSB} \geq 22 \mathrm{mg} / \mathrm{dL}$ were treated by exchange transfusion and phototherapy. Those with levels ranging from $13-21 \mathrm{mg} / \mathrm{dL}$ were treated by phototherapy only, except for some premature infants in whom exchange transfusion was done at levels lower than 22 $\mathrm{mg} / \mathrm{dL}$. For sick and /or premature infants, lower levels of TSB were regarded as a threshold for management (phototherapy and exchange transfusion). In infants who were admitted for exchange transfusion, the umbilical vein was catheterized, and used for exchange transfusion. The process of exchange transfusion is done by the resident 
doctors. blood used for laboratory investigations was taken from the first $20 \mathrm{ml}$ drawn from the patient (in case of exchange transfusion) and distributed into 5 tubes (for $\mathrm{CBC}$ and reticulocyte count, G6PD enzyme assay, blood culture, direct Coombs test, and biochemical measures). The tubes were sent to the laboratory immediately or stored in a refrigerator till the next morning (if the exchange transfusion is done at night). All the infants who required exchange transfusion were put on a broad-spectrum antibiotic cover of a combination of the

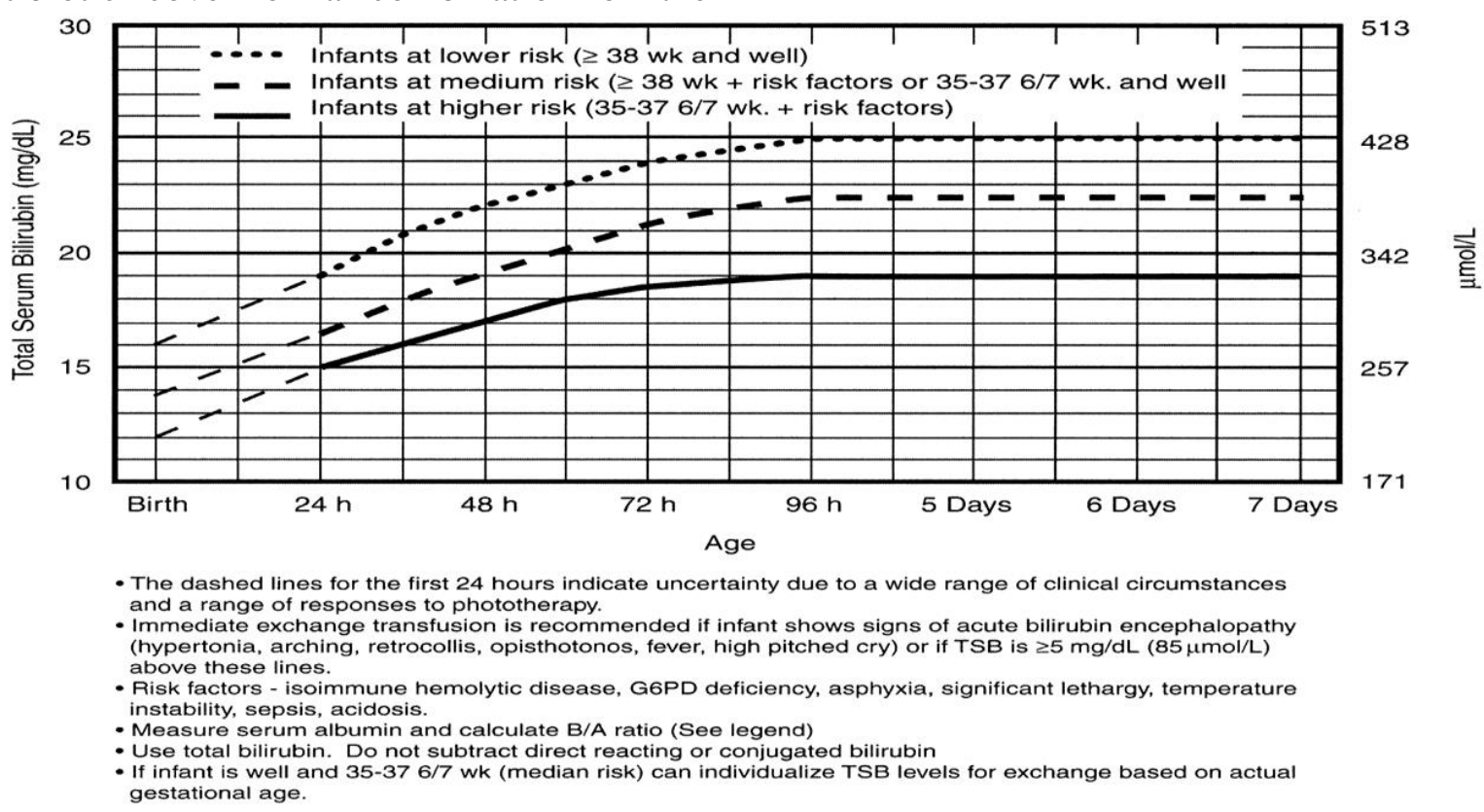

Figure (1):Guidelines for phototherapy in hospitalized infants of 35 or more weeks' gestation [14]

Table (1): Suggested Maximal Indirect Serum Bilirubin Concentrations (mg/dL) in Preterm Infants for exchange transfusion [14]

\begin{tabular}{|c||c||c||}
\hline BIRTH WEIGHT $(\mathrm{g})$ & UNCOMPLICATED & COMPLICATED* \\
\hline \hline$<1,000$ & $12-13$ & $10-12$ \\
\hline \hline $1,000-1,250$ & $12-14$ & $10-12$ \\
\hline \hline $1,251-1,499$ & $14-16$ & $12-14$ \\
\hline \hline $1,500-1,999$ & $16-20$ & $15-17$ \\
\hline \hline $2,000-2,500$ & $20-22$ & $18-20$ \\
\hline
\end{tabular}

*Complications include perinatal asphyxia, acidosis, hypoxia, hypothermia, hypoalbuminemia, meningitis, intraventricular hemorrhage, hemolysis, hypoglycemia, or signs of kernicterus. Phototherapy is usually started at $50-70 \%$ of the maximal indirect level 
Their eyes were covered and the rest of the body was exposed. They were kept under observation for about $24 \mathrm{hr}$. after the lamps were switched off for the possibility of rebound hyperbilirubinemia. Should TSB have remained relatively low, the infants were discharged home. The patients were divided into 2 groups:

Group A: includes infants who were treated by exchange transfusion and phototherapy. Group B: includes infants treated by phototherapy only.

After exchanging transfusion infants were followed up clinically and by investigations which include CBC, serum electrolytes, serum calcium, and blood sugar and with blood culture when indicated. Rhisoimmunization was diagnosed when the mother is $\mathrm{Rh}-\mathrm{ve}$ and the infant is $\mathrm{Rh}+\mathrm{ve}$ with a positive direct Coombs test (21). We

Table (2): Number of neonates and gender distribution

\begin{tabular}{|c|c|c|c|}
\hline & Group $\mathrm{A}(\mathrm{n}=44) \quad \%$ & Group B $(\mathrm{n}=56) \quad \%$ & $\operatorname{Total}(\mathrm{n}=100) \%$ \\
\hline Male & $3030 \%$ & $37 \%$ & $6767 \%$ \\
\hline Female & $1414 \%$ & 19 & $3333 \%$ \\
\hline M:F ratio & $1.11: 1$ & $1.48: 1$ & $2.03: 1$ \\
\hline Total & $4444 \%$ & $5656 \%$ & $100100 \%$ \\
\hline
\end{tabular}

* $\mathrm{P}=0.450$ (Not significant)

Table (3) showed the clinical characteristics of the babies in both groups on admission.

Table (3): Clinical characteristics of neonates in both studied groups

\begin{tabular}{|l||c|c||}
\hline Characteristics & Group A & Group B \\
\hline \hline Age on admission (hr) (mean \pm SD) & $101.6 \pm 42$ & $136.1 \pm 52$ \\
\hline \hline Gestational age (week) (mean \pm SD) & $36.12 \pm 2.5$ & $37.92 \pm 2.3$ \\
\hline \hline Body weight on admission (g) (mean \pm SD) & $2635 \pm 648$ & $2956 \pm 742$ \\
\hline
\end{tabular}

Table (4) showed the different causes of hyperbilirubinemia in the neonates of both

groups and their frequency, where hemolytic causes and prematurity predominant 
Table (4): Causes of hyperbilirubinemia in both studied groups

\begin{tabular}{|c|c|c|c|}
\hline Diagnosis & Group A (n-44) & Group B $(\mathrm{n}=56)$ & $\mathrm{P}$ value \\
\hline Rh-isoimmunization & $9(20.4 \%)$ & $4(7.14 \%)$ & $0.041 *$ \\
\hline ABO-incompatibility & $4(9.09 \%)$ & $6(10.71 \%)$ & 0.615 \\
\hline G6PD-deficiency & $12(27.27 \%)$ & $13(23.21 \%)$ & 0.724 \\
\hline Sepsis (culture +ve) & $3(6.81 \%)$ & $5(8.92 \%)$ & 0.976 \\
\hline Preterm & $12(27.27 \%)$ & $21(37.5 \%)$ & 0.813 \\
\hline $\begin{array}{l}\text { Healthy term neonate with no evidence of } \\
\text { hemolysis }\end{array}$ & $3(6.81 \%)$ & $7(12.5 \%)$ & 0.057 \\
\hline $\begin{array}{l}\text { Congenital infection (CMV IgM, IgG antibody } \\
\text { positive) }\end{array}$ & $1(2.27 \%)$ & $0(0 \%)$ & - \\
\hline "Hemolytic cause & $25(56.81 \%)$ & $23(41.00 \%)$ & $0.032 *$ \\
\hline
\end{tabular}

*p< 0.05 is significant

Table (5) showed the clinical and laboratory data of neonates with $\mathrm{Rh}$-isoimmunization in both groups where missed anti-D and previously affected baby is predominant

Table (5): Clinical associations of 13 neonates with Rh-isoimmunization

\begin{tabular}{|c|c|c|c|}
\hline Clinical association & Group A $(n=9) \%$ & Group B $(n=4) \%$ & $\mathrm{P}$ value \\
\hline Strongly positive direct Coombs test $(\geq++)$ & $(44.4 \%)$ & $(0 \%)$ & - \\
\hline Previously affected sibling & $(66.6 \%)$ & (50\%) & .157 \\
\hline Not exposed to Rh antigen & $(0 \%)$ & $(0 \%)$ & - \\
\hline $\begin{array}{l}\text { Mother has missed at least one dose of Anti- } \\
\text { D }\end{array}$ & $(9 \%)$ & $(25 \%)$ & .011 \\
\hline Onset of jaundice $\left(1^{\mathrm{st}}\right) 24 \mathrm{hr}$ & $(44.4 \%)$ & $(0 \%)$ & - \\
\hline Pallor & $(33.3 \%)$ & $(25 \%)$ & .317 \\
\hline $\mathrm{PCV}(\mathrm{mean} \pm \mathrm{SD})$ & $32.64 \pm 6.1 \%$ & $40.33 \pm 3.7 \%$ & - \\
\hline Reticulocytes(mean \pm SD) & $15.31 \pm 4.2 \%$ & $8.48 \pm 1.7 \%$ & - \\
\hline
\end{tabular}

Table (6) showed the number of exchange transfusion required in the 44 neonates in the study. There were 51process of exchange transfusion. $615.7 \%$ of the Group A)

Table (6): The number of exchange transfusion required in the 44 neonates

\begin{tabular}{||l||c|c|c|c||}
\hline \multicolumn{1}{|c||}{ CAUSE } & $\begin{array}{c}\text { One exchange } \\
\text { Transfusion }\end{array}$ & $\begin{array}{c}\text { Two exchange } \\
\text { Transfusions }\end{array}$ & $\begin{array}{c}\text { Three exchange } \\
\text { transfusions }\end{array}$ & $\begin{array}{c}\text { P } \\
\text { value }\end{array}$ \\
\hline \hline Rh-isoimmunization & 9 & 3 & 1 & .018 \\
\hline \hline ABO-incompatibility & 4 & 1 & 0 & - \\
\hline \hline G6PD & 12 & 0 & 0 & - \\
\hline \hline Sepsis & 3 & 0 & 0 & - \\
\hline \hline Preterm & 12 & 2 & 0 & - \\
\hline \hline Healthy term infants & 3 & 0 & 0 & - \\
\hline \hline Congenital CMV infection & 1 & 0 & 0 & - \\
\hline \hline Total & 44 & $6(15.7 \%)$ & $1(2.6 \%)$ & .000 \\
\hline
\end{tabular}

Neonatal septicemia with positive blood culture was found in 8 infants of both groups. Their clinical features are shown in Table (7). required two exchange transfusions, and one neonate $(2.6 \%$ of the Group A) required three exchange transfusions.
The two deaths were both males and death occurred after exchange transfusion. The cause of death was sepsis. 
Table (7): Features of 8neonates with positive blood culture in both groups

\begin{tabular}{|c|c|c|}
\hline Feature & Group A $(n=3)$ & Group B(n=5) \\
\hline Male: Female ratio & $2: 1$ & $4: 1$ \\
\hline "Gestational age (mean \pm SD $)$ & $35.25 \pm 2.5 \mathrm{wk}$ & $37.3 \pm 1.4 \mathrm{wk}$ \\
\hline $\begin{array}{l}\text { Blood culture: } \\
\text { a. Escherichia Coli } \\
\text { b.Group B streptococcus } \\
\text { c. Klebsiella }\end{array}$ & \begin{tabular}{l}
\multicolumn{3}{l}{ Male Female } \\
$2(66.6 \%) \quad 0(0 \%)$ \\
$0(0 \%) \quad 1(33.4 \%)$ \\
$0(0 \%)$
\end{tabular} & \begin{tabular}{lc}
\multicolumn{2}{l}{ Male Female } \\
$1(20 \%)$
\end{tabular} \\
\hline Death & $2(66.6 \%)$ & $0(0 \%)$ \\
\hline
\end{tabular}

Prematurity was found to be the cause of hr. Those who were treated with hyperbilirubinemia in 33 infants, their phototherapy alone were kept under clinical and laboratory characteristics were phototherapy for a mean of 78.32 hours, with shown in Table (8). The duration of an interruption for feeding and changing phototherapy after exchange transfusion had diapers. ranged from 1 to 6 days with a mean of 66.46

Table (8): Clinical characteristics of 33 premature infants in both groups

\begin{tabular}{|l||l||l||l||}
\hline Clinical and lab. findings & Group A(n = 12) & Group B $(\mathrm{n}=21)$ & Total $(\mathrm{n}=33)$ \\
\hline \hline Male: Female ratio & $1: 1$ & $1.33: 1$ & $1.20: 1$ \\
\hline \hline Gestational age(mean \pm SD) & $33.58 \pm 3.21 \mathrm{wk}$ & $34.72 \pm 2.74 \mathrm{wk}$ & $33.11 \mathrm{wk}$ \\
\hline \hline $\begin{array}{l}\text { Body weight on admission } \\
(\text { mean } \pm \text { SD) }\end{array}$ & $1755 \pm 452 \mathrm{gm}$ & $2117 \pm 365 \mathrm{gm}$ & $1988 \mathrm{gm}$ \\
\hline \hline Total Serum bilirubin $($ mean \pm SD) & $19.8 \pm 2.8 \mathrm{mg} / \mathrm{dL}$ & $14.4 \pm 3.8 \mathrm{mg} / \mathrm{dL}$ & $16.8 \mathrm{mg} / \mathrm{dL}$ \\
\hline
\end{tabular}

Table (9) showed the complications exchange transfusion while fever and loose encountered during the treatment course, stools complicating phototherapy where transient bradycardia following

Table (9): Complications of the 44 exchange transfusions and phototherapy

\begin{tabular}{|c|c|c|}
\hline Complications of exchange transfusion & \begin{tabular}{|ll} 
Out of total no. of exchange transfusion No. $\%$ \\
\end{tabular} & P-value \\
\hline Transient bradycardia & $25(49.01 \%)$ & \multirow{7}{*}{.000} \\
\hline Cyanosis & $3(5.8 \%)$ & \\
\hline Apnea and bradycardia & $3(5.8 \%)$ & \\
\hline Hyperkalemia & $1(1.9 \%)$ & \\
\hline Hypocalcaemia & $2(3.8 \%)$ & \\
\hline Hypoglycemia & $3(5.8 \%)$ & \\
\hline $\begin{array}{l}\text { Others } \\
\text { Death (within } 24 \text { hours), } \\
\text { Thrombocytopenia, } \\
\text { Neutropenia }\end{array}$ & $\begin{array}{l}2(3.8 \%) \\
3(5.8 \%) \\
2(3.8 \%)\end{array}$ & \\
\hline Complications of phototherapy & & P-value \\
\hline Loose stool & $25(25 \%)$ & \multirow{4}{*}{.000} \\
\hline Erythematous rash & $14(14 \%)$ & \\
\hline Fever & $33(33 \%)$ & \\
\hline Hypothermia & $5(5 \%)$ & \\
\hline
\end{tabular}




\section{Discussion}

Hyperbilirubinemia was noticed in males more than females (67 males, with a male: female ratio 2.03: 1) in both groups (A and B). This may be a male gender is considered as a risk factor for neonatal jaundice, $[17,18]$ although no significant statistical difference was found. Alistair, showed that bilirubin was significantly higher in males than females. It may be related to the higher rate of prematurity in the males and G6PD deficiency (which is prevalent in males), or other factors [18]. The age at admission in both groups, are older than 4 days (101.6 hr. for group A and $136.1 \mathrm{hr}$ for group B). This might be due to the belief of families that jaundice is a normal phenomenon in the $1^{\text {st }}$ week of life, or parents try to consult a local health care centers initially instead of consulting pediatric hospitals, which results in a delay of presentation, as well as the use of non-medical and traditional methods to deal with jaundice like water and glucose and others (herbal medicine). However, the ages in group A were lower than in group B which may be explained partly by the higher incidence of hemolytic causes of jaundice in the first day of life. The mean gestational age was 36.12/52 in group A and 37.92/52 in group B. Those in group A appear to have a lower gestational age, which is probably related to the higher risk of jaundice in premature infants. The mean body weight for group A neonates was $2.635 \mathrm{gm}$ and for group B was $2.956 \mathrm{gm}$. It is clear that the gestational ages and body weights of group $\mathrm{A}$ patients were less than that in group B, which may explain their greater rate of exchange transfusion. Prematurity is a well-known risk factor for neonatal hyperbilirubinemia due to the more immaturity of the liver enzymes. [13, 16]. However, Al-Shujairy showed that the neonates who are treated by exchange transfusion were aged $127 \mathrm{hr}$ (mean), mean gestational age was 37.4/52, and the mean body weight was $2734 \mathrm{gm}$. This might be due to the chance effect, decreased health services, maternal distress both physical and psychological, which affect the birth weight and the gestational ages of the newborns. Hemolytic cause for jaundice was found in 48neonates (48\%); 25 (52.0\%) in group A and $23(47.9 \%)$ in group B with a P-value 0.032 which indicates a significant risk for hemolytic anemia to be exposed for exchange transfusion. Singhal and Kalkan found a hemolytic cause in $62.5 \%$ and $41 \%$ respectively $[15,16]$ of studied neonates, while Michael found that the hemolytic causes represent $34 \%$ of the causes[17]. These differences might be due to the small sample taken, different ethnic groups, geographic factors, or other factors.

$\mathrm{Rh}$-isoimmunization was found in $13 \%$, ABO-incompatibility in $10 \%$ and G6PDdeficiency in $25 \%$. Nine neonates with $\mathrm{Rh}$ isoimmunization were treated by exchange transfusion and 4 by phototherapy only with a P-value of 0.041 which indicates a significant risk for jaundiced neonates who have $\mathrm{Rh}$ isoimmunization to be treated by exchange transfusion. Michael found $\mathrm{Rh}$ isoimmunization represents $3 \%$ of the causes of severe neonatal hyperbilirubinemia. This difference may be related to the variations in the distribution of the $\mathrm{Rh}$ antigen, better prophylactic measures against $\mathrm{Rh}$ - 
isoimmunization diseases than in our locality. We found ABO- incompatibility in 10 infants, 4 of them were in group $A$ and 6 in group $\mathrm{B}$ with a $\mathrm{P}$-value of 0.615 . The $\mathrm{ABO}$ incompatibility is less severe than $\mathrm{Rh}$ isoimmunization, thus fewer neonates had severe jaundice that required exchange transfusion [17,18]. Michael found ABO incompatibility represents $19 \%$ of the causes of neonatal hyperbilirubinemia, possibly because it may represent the most common hemolytic cause of neonatal hyperbilirubinemia in the area of the study. We found $25(25 \%)$ neonates had G6PD enzyme deficiency, while Micheal found 7\% of the cases, and Al-Shujairy it represents 9\% of his cases. Sepsis present in 8 studied neonates (8\%), while Michael detected 6 cases of sepsis $(2.3 \%)$ which is probably due to better hygiene and medical care in the delivery rooms and their nurseries. In septicemia, male gender and prematurity are considered important risk factors $[13,17]$. Two neonates died; both had sepsis and died after exchange transfusion (within 24 hours) despite receiving combined antibiotics. Premature neonates represent $(33 \%)$ with a mean gestational age of 33.91/52 and the mean birth weight on admission was 1.988 gm, and the mean TSB was $16.8 \mathrm{mg} / \mathrm{dL}$. Michael detected 45 premature neonates $17 \%$ and their mean gestational age was 34.2/52, with a mean body weight of $2.187 \mathrm{gm}$, which reflects better antenatal care of the pregnant women, better nutrition, and health status. One patient was diagnosed with congenital CMV infection by clinical findings and positive CMV IgM, and received exchange transfusion once. Ten neonates $(10 \%)$ were full-term and healthy with no abnormal findings apart from jaundice and no evidence of hemolysis. No cause was found from the investigations. Many series in different parts of the world have some percentage of their neonates with no clear cause for hyperbilirubinemia. Exchange transfusion, abroad, is uncommonly used nowadays because of the use of intensive phototherapy and because sensitization is being prevented $[12,17]$. In this study six neonates required two exchange transfusions, three of them had Rh-isoimmunization, one had ABOincompatibility, and two infants were premature. However, one neonate with severe $\mathrm{Rh}$ isoimmunization required three exchange transfusions. The frequency of complications of the exchange transfusion in comparison to Al-Shujairy was nearly the same in both studies. Mortality following exchange transfusion was $3.8 \%$ which is higher than internationally accepted figures.

\section{Conclusions}

The cause of hyperbilirubinemia mayn't be taken into account especially at the start of treatment. Severe Rh-isoimmunization is still present in our locality. The mortality rate from exchange transfusion is higher than internationally accepted figures. The exchange transfusion is carried out more frequently than in other countries and done under nonstandard conditions which increases the risk of the associated complications.

\section{Recommendations}

The following recommendations may be drawn from this study:

1.Decisions for the treatment of the severely jaundiced neonates should not be made until 
full history, a physical examination is done, and the recommended laboratory investigations are performed.

2. Standard guidelines for the treatment of neonatal hyperbilirubinemia should be followed in the management of unconjugated hyperbilirubinemia.

3.Exchange transfusion must be done under optimal conditions of sterility, environmental regulation, and monitoring of electrolytes, calcium, blood glucose, body temperature, and vital signs.

4.Control programs for $\mathrm{Rh}$-isoimmunization should be improved in our country.

\section{References}

[1]Bhutani VK, Johnson L, Sivieri EM. Predictive ability of a predischarge hourspecific serum bilirubin for subsequent significant hyperbilirubinemia in healthy term and near-term newborns. Pediatrics 1999; 103:6.

[2]US Preventive Services Task Force. Screening of infants for hyperbilirubinemia to prevent chronic bilirubin encephalopathy: US Preventive Services Task Force recommendation statement. Pediatrics 2009; 124:1172

[3]Trikalinos TA, Chung M, Lau J, Ip S. Systematic review of screening for bilirubin encephalopathy in neonates. Pediatrics 2009; 124:1162.

[4]Maisels MJ, Bhutani VK, Bogen D, et al. Hyperbilirubinemia in the newborn infant > or $=35$ weeks' gestation: an update with clarifications. Pediatrics 2009; 124:1193.

[5]Johnson L, Bhutani VK, Karp K, et al. Clinical report from the pilot USA Kernicterus Registry (1992 to 2004). J Perinatol 2009; 29 Suppl 1:S25.
[6]Bental YA, Shiff Y, Dorsht N, et al. Bhutani-based nomograms for the prediction of significant hyperbilirubinaemia using transcutaneous measurements of bilirubin. ActaPaediatr 2009; 98:1902.

[7]De Luca D, Romagnoli C, Tiberi E, et al. Skin bilirubin nomogram for the first $96 \mathrm{~h}$ of life in a European normal healthy newborn population, obtained with multiwavelength transcutaneous bilirubinometry. ActaPaediatr 2008; 97:146.

[8]Varvarigou A, Fouzas S, Skylogianni E, et al. Transcutaneous bilirubin nomogram for prediction of significant neonatal hyperbilirubinemia. Pediatrics 2009; 124:1052.

[9]Kuzniewicz M, Newman TB. Interaction of hemolysis and hyperbilirubinemia on neurodevelopmental outcomes in the collaborative perinatal project. Pediatrics 2009; 123:1045.

[10]Jangaard KA, Fell DB, Dodds L, Allen AC. Outcomes in a population of healthy term and near-term infants with serum bilirubin levels of >or=325 micromol/L (>or=19 mg/dL) who were born in Nova Scotia, Canada, between 1994 and 2000. Pediatrics 2008; 122:119.

[11]Vandborg PK, Hansen BM, Greisen G, et al. Follow-up of neonates with total serum bilirubin levels $\geq 25 \mathrm{mg} / \mathrm{dL}$ : a Danish population-based study. Pediatrics 2012; 130:61.

[12]Erin E. Shaughnessy, Neera K. Goyal. The Newborn Infant. In Kliegman RM, Joseph W. ST Geme III, Nathan J. Blum, Samir S. Shah, Robert C. Tasker, Karen M. Wilson, Richard E. Behrman (editors). Nelson Textbook of Pediatrics. 21th ed. 
Philadelphia, PA: WB Saunders Co.; 2019:

ch.123.3,pp.4097-4207.

[13]Al-shujairy TI. Profile of management of indirect reacting neonatal hyperbilirubinemia. A thesis submitted to the Scientific Council Of Pediatrics in partial fulfillment for the Degree of fellowship of The Iraqi Commission For Medical Specialization in Pediatrics. 2001; supervised by Dr. Hussam Al-Charmockly, F.R.C.P.

[14]Johnson LH, Bhutani VK, Brown AK. System-based approach to management of neonatal jaundice and prevention of kernicterus. J Pediatr. 2002; 140:396 -403

[15] Singhal PK, Singh M, Paul VK, Deorari AK, Chorpade MG. Spectrum of neonatal hyperbilirubinemia: An Analysis of 454 cases. Indian-Pediatr 1992; 29(3): 319-325.

[16]Kalkan I, Heljec S, Kurtgic S. Neonatal Hyperbilirubinemia: evaluation and treatment. Med-Arch, 1999; 53(3): 43-45. [17]Michael S, Douglas C, Vibhuti S. Incidence and causes of severe neonatal hyperbilirubinemia in Canada. CMAJ September 12, 2006; 175 (6):343-346.

[18]Alistair GS. Bilirubin Metabolisim and jaundice.In Neonatology. A Practical Guide, 1sted.,W.b. Saunder Co.;1996:134-149. 